\title{
Fatores que explicam a percepção da efetividade da avaliação do estágio probatório em uma instituição pública federal
}

\author{
Luciana Cristina Silva da Luz \\ Universidade Federal de Pernambuco (UFPE) \\ Dalson Britto Figueiredo Filho \\ Universidade Federal de Pernambuco (UFPE)
}

Considerando que o contexto social exerce influência sobre a efetividade da avaliação de desempenho (LEVy; WILLIAMS, 2004) e a escassez do tema em pesquisas científicas, este artigo busca identificar que fatores explicam a percepção da efetividade da avaliação do estágio probatório. A hipótese é de que elementos contextuais são mais importantes do que variáveis individuais (SANTOS, 2005). A pesquisa utilizou um survey entre 24 de novembro e 30 de dezembro de 2015, com 550 servidores da Universidade Federal de Pernambuco. A análise fatorial identificou quatro dimensões: efetividade da avaliação do estágio probatório, suporte da instituição, ação gerencial e valorização do estágio probatório enquanto avaliação. Em seguida, um modelo de regressão linear estimou o efeito dessas dimensões e das variáveis individuais sobre a percepção da efetividade. Os principais resultados indicam que fatores contextuais exercem maior impacto do que variáveis pessoais, e o suporte da instituição foi a dimensão mais importante.

Palavras-chave: estágio probatório, avaliação de desempenho, efetividade, administração pública

[Artigo recebido em 3 de março de 2017. Aprovado em 5 de julho de 2018.] 
Factores que explican la percepción de la efectividad de la evaluación de la etapa probatorio en una institución pública federal

Considerando que el contexto social influye en la efectividad de la evaluación de desempeño (LEVY; WILLIAMS, 2004) y la escasez del tema en investigaciones científicas, este artículo busca identificar qué factores explican la percepción de la efectividad de la evaluación de la etapa probatoria. La hipótesis es que elementos contextuales son más importantes que variables individuales (SANTOS, 2005). La encuesta utilizó una encuesta entre el 24 de noviembre y el 30 de diciembre de 2015, con 550 servidores de la Universidad Federal de Pernambuco. El análisis factorial identificó cuatro dimensiones: efectividad de la evaluación de la etapa probatoria, apoyo de la institución, acción gerencial y valorización de la etapa probatoria como evaluación. A continuación, un modelo de regresión lineal estimó el efecto de esas dimensiones y de las variables individuales sobre la percepción de la efectividad. Los principales resultados indican que factores contextuales ejercen mayor impacto que variables personales y el soporte de la institución fue la dimensión más importante.

Palabras clave: etapa probatoria, evaluación del desempeño, efectividad, administración pública

Factors explaining the perception of the effectiveness of evaluation of the probationary stage in a federal public institution

Considering that the social context influences the effectiveness of performance evaluation (LEVY; WILLIAMS, 2004) and the scarcity of the topic in scientific research, this article seeks to identify which factors explain the perception of the effectiveness of the evaluation of the probationary stage. The hypothesis is that contextual elements are more important than individual variables (SANTOS, 2005). The survey used a survey between November 24 and December 30, 2015, with 550 servers from the Federal University of Pernambuco. Factor analysis identified four dimensions: evaluation effectiveness of probationary period, institution support, management action and evaluation of probationary period as evaluation. Then, a linear regression model estimated the effect of these dimensions and the individual variables on the perception of effectiveness. The main results indicate that contextual factors have greater impact than personal variables and Institutional Support was the most important dimension.

Keywords: probationary stage, performance evaluation, effectiveness, public administration 


\section{Introdução}

O estágio probatório é um dos mecanismos de acesso meritocrático ao serviço público e tem o objetivo de formar uma burocracia profissional (SUDANO, 2011; PACHeCo, 2010; BitTencourt, 1948). No entanto, a literatura aponta diferentes limitações que comprometem a efetividade desse dispositivo. Por exemplo, a ausência de indicadores objetivos e diretamente mensuráveis (RIBEIRO, 1945; BITTENCOURT, 1948; MAIA, 1958), a falta de instrumentos de controle e monitoramento (BITTENCOURT, 1948) e entraves de natureza cultural (MAIA, 1958; FICAGNA et al., 2014; SILVA, 2016).

Segundo Maia (1958) e Modesto (2007), a experiência brasileira histórica revela que o avaliado era confirmado no cargo sem passar por um processo de avaliação de fato. Ou seja, ao longo do tempo, a avaliação de desempenho se apresenta mais como uma exigência formal, transcorrendo quase sempre sem qualquer influência na vida funcional do servidor (MODESTO, 2007; FICAGNA et al., 2014; PINTO; BEHR, 2015). Para superar esses problemas, algumas mudanças institucionais foram implementadas. Por exemplo, a Emenda Constitucional (EC) no 19 (1998) acrescentou o período de três anos de efetivo exercício e tornou obrigatória a avaliação especial de desempenho para aquisição da estabilidade ${ }^{1}$. Curiosamente, apesar da sua importância para melhorar a qualidade da burocracia, ainda são escassos os trabalhos que abordam o estágio probatório e sua avaliação, sobretudo após as alterações sofridas na Reforma Administrativa².

Diante desse cenário, este artigo analisa os fatores que explicam a percepção da efetividade da avaliação do estágio probatório. Definimos efetividade como sendo uma avaliação da qualidade dos serviços públicos e, através desse conceito, reacende-se o entendimento de que o governo deve prestar melhores serviços (ABRUCIO, 2006). Metodologicamente, adota-se uma perspectiva multimétodo para testar a hipótese de que fatores contextuais são mais importantes do que variáveis pessoais. Em particular, o desenho de pesquisa combinou estatística descritiva, multivariada, análise documental e observação não participante. Os dados foram coletados entre os dias 24 de novembro e 30 de dezembro de 2015, de maneira presencial, através de um survey realizado com 550 servidores técnicoadministrativos da Universidade Federal de Pernambuco (UFPE). As respostas foram submetidas à análise fatorial que identificou quatro dimensões: efetividade da avaliação do estágio probatório, suporte da instituição, ação gerencial e valorização do estágio probatório enquanto avaliação. Por fim, utilizamos um modelo de

\footnotetext{
${ }^{1}$ Disponível em: http://www.planalto.gov.br/ccivil_03/Constituicao/Emendas/Emc/emc19.htm

2 Importantes exceções podem ser encontradas em: Sudano (2011); Bezerra (2013); Ficagna (2014); Silva (2016).
} 
regressão linear múltipla para mensurar o efeito das dimensões encontradas sobre a percepção da efetividade da avaliação do estágio probatório.

O restante do artigo está organizado da seguinte forma: a próxima seção apresenta um levantamento sistemático do estágio probatório no direito comparado e na legislação nacional. Depois disso, discutimos o papel do estágio probatório como mecanismo de avaliação de desempenho. A terceira seção apresenta as principais características do desenho de pesquisa com o objetivo de aumentar a transparência e garantir a replicabilidade dos resultados. Em seguida, apresentamos os resultados. A última seção sumariza as conclusões.

\section{Estágio probatório: uma perspectiva comparada}

O estágio probatório surge em meio às discussões sobre a inserção e ampliação do sistema de mérito no serviço público (SUDANO, 2011). Esse período possui uma finalidade prática, a qual verifica requisitos não mensuráveis nos processos comuns de seleção (Elliot; PeAton, 1994; Alves, 2007; Modesto, 2007). Teoricamente, o estágio probatório permite a avaliação de características pessoais e qualidades que não podem ser aferidas por meio de testes ou outros exames técnicos. Possibilita uma validação na totalidade do processo de seleção e uma oportunidade para remediar colocações estranhas ou inapropriadas (FIGUEIREDO, 1943; RIBEIRO, 1945; MAIA, 1958; StAHL, 1983 apud ElLIOT; PEATON, 1994).

De acordo com Abrucio (2014), esses mecanismos e os de promoção foram introduzidos ao longo do século 20 para evitar tanto o patrimonialismo, ou seja, a confusão entre o patrimônio público e o privado (BRESSER PEREIRA, 1998a), como para garantir funcionários capazes de ofertar serviços de melhor qualidade à sociedade (ABrucio, 2007; CAVALCANTE; CARVAlHo, 2017).

Tomando como referência o funcionalismo público em outros países, a experiência dos Estados Unidos revela que nem sempre a meritocracia foi norteadora das normas de ingresso no sistema público de emprego (JOHNSON; LibeCAP, 1994; CAVAlCANTE; CARVAlho, 2017) ${ }^{3}$. O favoritismo político e o empreguismo era quem ditava as regras de acesso aos cargos na burocracia, a atividade partidária era um pré-requisito para a admissão nos órgãos estatais, que significava o mesmo que serviço ao partido ${ }^{4}$; isso ocorreu até a instauração da lei de Pendleton, em 1883, a qual foi implementada para modificar esse cenário (ElLIOT; PEATON, 1994; Johnson; LIBECAP, 1994; RodRIgUeS, 1995). Através

\footnotetext{
${ }^{3}$ Ver Wheeler (1919) para um dos trabalhos seminais sobre o assunto, a partir da realidade norte-americana.

${ }^{4} \mathrm{O}$ sistema predominante até aquela data era o chamado de spoils system, e caracterizava-se pelos benefícios proporcionados às lideranças políticas; a cada troca de partido predominante no governo, eram substituídos os ocupantes dos cargos públicos (RODRIGUES, 1995).
} 
da Comissão de Serviço Civil dos Estados Unidos, deu-se início à criação de uma burocracia capacitada, estimulando-se a profissionalização do Serviço Público e fornecendo-se condições para a formação de carreira, além de estabelecerem-se instrumentos para seleção de profissionais competentes ${ }^{5}$.

Entre as ações implementadas, instaurou-se um período probatório que faria parte da seleção, sem o qual nenhuma nomeação seria definitiva ${ }^{6}$. Esse tempo é constituído pelos primeiros seis meses de serviço, durante o qual é possível que a Comissão e os departamentos interessados fixem um prazo maior, podendo ser variável entre os Estados, cidades e em relação ao tipo de trabalho (BITTENCOURT, 1948; ELLIOT; PEATON, 1994). Quanto à duração praticada em alguns estados, destacavam-se: Alabama - seis meses, no mínimo, podendo o diretor de pessoal determinar maior prazo; Massachussets - era determinado pela agência central; Connecticut - três a seis meses (FIgueIREDo, 1943; Ribeiro, 1945; BitTEnCOURT, 1948).

De acordo com Rodrigues (1995), quando um servidor completa com sucesso seu período de estágio probatório, torna-se efetivo e não estável. Segundo o autor, a palavra "estabilidade" nem aparece no texto da lei. Caso o funcionário não seja considerado com condições para exercer o cargo, poderá ser exonerado mesmo sendo aprovado nas provas. Com base em avaliação, a administração determinará se esse será ou não efetivado, por meio de justificativa escrita, emitida pelo superior imediato (RODRIGUES, 1995). Após a sua aprovação, adquire direitos adicionais (ELLIOT; PEATON, 1994).

Mesmo após sua efetivação, o trabalhador não possui garantia contra demissões, principalmente se apresentar um desempenho insuficiente, sob os parâmetros do sistema7. Para proporcionar a eficiência do serviço, indivíduos poderão ser dispensados pelo governo com a prerrogativa da lei. Tais procedimentos são conduzidos de forma a não resguardar os ineficientes nem provocar injustiças (RODRIGUES, 1995).

\footnotetext{
${ }^{5}$ Lei federal norte-americana promulgada em 16 de janeiro de 1883, estabeleceu a Comissão de Serviço Civil dos Estados Unidos, a qual instauraria e gerenciaria o sistema de mérito voltado para o recrutamento e promoção dos funcionários. Entre outras normas, instituiu um período de prova, para que a nomeação se tornasse permanente (RodRIGUES, 1995). Disponível em: http://www.ourdocuments.gov/doc.php?flash=true\&doc=48

${ }^{6}$ Apesar da lei de Pendleton instituir o período probatório, apenas em 1940, com as Regras do Serviço Civil, é que esse mecanismo foi regulamentado. De acordo com essas regras, o servidor indicado a ser nomeado deverá receber um certificado de nomeação probatória; seis meses é o período mínimo, podendo a Comissão estabelecer tempo mais longo (BITTENCOURT, 1948).

${ }^{7}$ No caso de demissão, a lei garante os seguintes direitos para o servidor concursado: trinta dias de aviso prévio, no mínimo, com os motivos de sua demissão apresentados por escrito; prazo de sete dias para contraditório por escrito e verbal; direito a recorrer ao Conselho de Proteção do Sistema de Mérito, concedendo audiência e um advogado e da decisão do Conselho no Tribunal de Recursos dos Estados Unidos, que poderá autorizar novas audiências (RODRIGUES, 1995).
} 
Em alguns países, conforme relatou Bittencourt (1948), a principal característica era de que o período probatório normalmente era variável e tinha no mínimo seis meses, podendo aumentar dependendo das atividades, como era o caso da Austrália, Canadá, Uruguai, Itália e dos Estados Unidos (BItTencourt, 1948; Elliot; PeATon, 1994). Na França existiam as seguintes abordagens: uma buscava o treinamento, e a outra era complementar à seleção (BITTENCOURT, 1948). Diferente do que ocorre no Brasil, a demonstração da capacidade prática e efetiva não era suficiente, sendo obrigatório um exame final. Já no modelo alemão havia inicialmente uma seleção e em seguida uma preparação teórica com a prática.

No Brasil, até praticamente a instauração da EC no 19 (1998), o estágio probatório pouco evoluiu nem recebeu a devida atenção da administração pública. De acordo com Bittencourt (1948), o dispositivo legal que primeiro tratou do período que o servidor deveria cumprir a título precário quando fosse nomeado em cargo público, apesar de não trazer a expressão estágio probatório, foi a Lei no 284 , de 1936, a qual declarava ${ }^{8}$ :

Art. 40 A primeira nomeação, para qualquer cargo público, mesmo provido por concurso, será feita, a título precário, por dois anos, respeitadas as disposições constitucionais.

Já estabelecido como estágio probatório, foi empregado na legislação brasileira pela primeira vez com o Estatuto dos Funcionários Públicos da União, o Decretolei (DL) no 1.713, de 28 de outubro de 1939, que o definiu como um período de experiência a que todo funcionário, cuja nomeação seja para cargo público de provimento efetivo, isolado ou de carreira, terá apurada a conveniência de sua confirmação, analisando-se os requisitos: idoneidade moral; aptidão; disciplina; assiduidade, dedicação ao serviço e eficiência?

No entanto, ao longo dos anos, deixou de ser um mecanismo de avaliação do servidor recém-ingresso ao serviço público para ser mais uma etapa burocrática a ser cumprida (AlVES, 2007; Modesto, 2007). Através da EC no 19 (1998) foi estabelecida outra perspectiva para esse dispositivo: a) aumentou o período para três anos de efetivo exercício; b) tornou clara e restrita a aplicação do estágio probatório e da estabilidade a cargos efetivos nomeados por meio de concurso público; e c) incluiu ainda uma avaliação de desempenho obrigatória, feita por uma comissão, na qual apenas quem é aprovado tem acesso à estabilidade ${ }^{10}$.

\footnotetext{
8 Disponível em: http://www2.camara.leg.br/legin/fed/lei/1930-1939/lei-284-28-outubro-1936503510publicacaooriginal-1-pl.html

${ }^{9}$ Disponível em: http://www.planalto.gov.br/ccivil_03/decreto-lei/1937-1946/Del1713.htm

${ }^{10}$ Disponível em: http://www.planalto.gov.br/ccivil_03/Constituicao/Emendas/Emc/emc19.htm
} 
Tais ações demonstraram uma tentativa de melhorar a utilidade desse instrumento, que, desde sua criação em 1939, continuava funcionando com as mesmas prerrogativas, sem de fato atuar como um período de análise do servidor, antes de sua efetivação no cargo (ALVES, 2007; Modesto, 2007). De acordo com Bresser Pereira (1998), a EC no 19 (1998) foi um dos alicerces da reforma administrativa, promovendo uma importante mudança institucional. A modificação feita no estágio probatório, exigindo uma avaliação para o servidor adquirir a estabilidade, foi um dos principais pontos dessa reforma.

\section{O estágio probatório e a inserção da avaliação de desempenho}

A avaliação de desempenho de servidores pode ser classificada como um mecanismo de gestão próprio do conceito da Nova Gestão Pública (NGP) ou, no caso brasileiro, da administração pública gerencial (REZENDE, 2004; BRESSER PEREIRA, 2006) ${ }^{11}$. É um tipo da categoria avaliação de desempenho, que é composta não apenas por pessoas, mas por processos, programas, instituição. Está relacionada com os valores da NGP, os quais, entre outros fatores, priorizam os resultados, transferindo o foco dos agentes públicos para os fins e não os meios (REZENDE, 2004; Bresser Pereira, 2006; Bergue, 2014; Cavalcante; Carvalho, 2017).

Para abordar a avaliação de desempenho, é necessário distinguir sua definição da gestão de desempenho. A gestão do desempenho é um somatório de atividades que visam melhorar o desempenho tanto individual quanto de equipes de trabalho (DENISI, 2000) e posteriormente da organização (DENISI; PRITCHARD, 2006). Por sua vez, a avaliação de desempenho (AD) caracteriza-se pelos procedimentos utilizados na organização para medir o grau de desempenho dos empregados (DIJK; SCHODL, 2015). Neste estudo será adotada a perspectiva de Denisi (2000), segundo a qual a $A D$ refere-se ao método utilizado pela organização que busca mensurar, por meio de notas, o nível de desempenho de uma pessoa ou grupo, tendo como propósito melhorar a efetividade organizacional.

Quanto ao desempenho, será utilizado o conceito proposto por Sonnentag e Frese (2002): uma ação ou uma série delas realizadas por um indivíduo na situação de trabalho que contribuem para o alcance de objetivos organizacionais, as quais podem ser medidas e julgadas. A Avaliação de Desempenho, portanto, apresenta como foco principal acompanhar e analisar a forma como o trabalhador atua em suas atividades e os objetivos alcançados. Tem o intuito de adquirir um diagnóstico dos fatores que favorecem ou dificultam o alcance dos resultados e, através deste, criar planos de

\footnotetext{
${ }^{11}$ New Public Management, termo caracterizado por um conjunto de medidas para alterar as formas de atuação do Estado (PACHECO, 2010).
} 
ação para atingir as metas estabelecidas e valorizá-las, bem como recompensar a atuação profissional (ESCOLA NACIONAL DE AdMINSTRAÇÃo PúBLICA, 2003).

Esse dispositivo deve ser entendido como um processo que é iniciado com o planejamento e termina com a comparação entre o executado e o planejado (GUIMARÃES; NADER; RAMAGEM, 1998). A AD possui duas perspectivas: a primeira é vista como instrumento de desenvolvimento de recursos humanos. Nesse caso, ela seria de interesse do funcionário por ser o meio através do qual ele se beneficiaria com treinamentos, prêmios e reconhecimento em geral. A outra concepção a coloca como mecanismo de controle. Através dela, a instituição não apenas registra o que o indivíduo faz, mas verifica como ele realiza seu trabalho, identificando ainda quais aspectos podem ser corrigidos ou melhorados através do desenvolvimento (GUIMARÃES; NADER; RAMAgEM, 1998; GUIMARÃES; LeITÃO; LOURENÇO, 1999).

Contudo, algumas dificuldades são comuns na operacionalização desses sistemas de avaliação: a) utilização de critérios comportamentais, sem ligar a avaliação individual e institucional; b) indicadores de desempenho baseados em cargos genéricos e não na atividade realizada; c) ausência de ferramentas e procedimentos sistemáticos que permitam o julgamento do desempenho do servidor ou utilização de mecanismos difíceis de serem compreendidos; d) uso de apenas um método para diferentes grupos de cargos ou utilização exagerada de distintos formulários; e) medidas de desempenho altas ou baixas, estabelecidas de maneira subjetiva; f) desconsideração de variáveis de contexto, onde as atividades são realizadas, que influenciam o desempenho; g) resistência, descrença, insatisfação dos servidores quanto à avaliação; h) falta de acompanhamento e conhecimento do desempenho do avaliado pelo avaliador e ausência de comunicação entre eles (ODELIUS, 2000).

De acordo com Oliveira-Castro, Lima e Veiga (1996), um sistema de AD, para ser efetivo e bem-sucedido, deve respeitar as características culturais da instituição que o adota. Até os modelos mais avançados podem fracassar se as práticas informais de avaliação forem inadequadas. São comuns sentimentos de injustiça e iniquidade em culturas de leniência ou superavaliação ${ }^{12}$. A prática da leniência, muito comum no serviço público, causa inúmeros danos. É responsável por prejuízos como um todo, sobretudo nos trabalhadores mais dedicados, causando desmotivação e redução da produtividade.

O objetivo final da avaliação de desempenho deve ser o de proporcionar informações que possibilitem aos gestores gerir de forma a melhorar o desempenho do empregado (DENISI; PrITCHARD, 2006). Dijk e Schodl (2015) sugerem três mecanismos: 1) as informações fornecidas podem subsidiar decisões

\footnotetext{
12 Nessas situações, independente do desempenho, seja competente, descompromissado, incompetente ou indiferente, todos recebem avaliação máxima (OLIVEIRA-CASTRO; LIMA; VEIGA, 1996).
} 
administrativas que associam desempenho analisado a punições e recompensas (aumento de salário e promoções); 2) fornecimento de feed back de desenvolvimento (direcionado a elevar a capacidade de executar) (RYNES; GERHART; PARKS, 2005); e 3) a própria avaliação é um processo que promove a sensibilização dos funcionários para o fato de que eles estão sendo medidos (DIJK; SCHODL, 2015). Os indivíduos tendem a elevar seus níveis de cooperação quando sabem que seu comportamento está sendo observado (BATESON et al., 2006). Os dois primeiros mecanismos são bastante estudados, o terceiro tem sido pouco discutido na literatura.

Para Deadrick \& Gardner (2008), na avaliação de desempenho do indivíduo no trabalho, a mudança do desempenho deve ser considerada e analisada ao longo do tempo, a partir dos fatores relacionados ao contexto da organização ou ambiente de trabalho e diferenciada daquelas relacionadas à pessoa. Assim, para que discrepâncias sejam adequadamente identificadas, é preciso apontar quais restrições impostas pelo ambiente de trabalho interferem no desempenho satisfatório.

De acordo com Oliveira-Castro, Lima e Veiga (1996), tais fatores podem fazer parte de diversos níveis de análise: do mais abrangente, como o extraorganizacional (situação econômica do país, oferta de mão de obra, de empregos, legislação trabalhista) e o organizacional (clima e cultura organizacionais, políticas e práticas de administração e benefícios, desenvolvimento de pessoas, imagem da organização na sociedade, sistemas de promoções funcionais), ou os mais específicos, como os níveis representados pelo ambiente de tarefas (características do trabalho, tipo de relacionamento interpessoal do grupo no trabalho, qualidade da comunicação entre chefia e avaliado, adequação do ambiente físico) e pelas características do trabalhador (personalidade, habilidades, conhecimentos, atitude, idade, sexo, escolaridade, motivações, estilo cognitivo, aparência pessoal, entre outros).

Nessa mesma direção, nos últimos anos pesquisas começaram a estudar os efeitos do contexto social sobre o processo de avaliação de desempenho (AD) (LEVY; WILliAMS, 2004). Tal perspectiva considera que essa avaliação ocorre em um contexto especifico, e, para o seu sucesso, é fundamental entender o contexto social (DIJK; SCHODL, 2015).

Por exemplo, Levy e Williams (2004) identificaram o efeito do contexto social, ou seja, as circunstâncias em que ocorrem as avaliações, sobre o processo de AD, e como essa temática está sendo abordada na literatura. A pesquisa identificou uma maior consciência quanto à importância do contexto social nesse processo de avaliação, destacando três aspectos: 1) ampliou o conceito de efetividade da AD, enfatizando as reações dos avaliados; 2) observou a importância da influência do ambiente e da cultura de feedback sobre os resultados das avaliações; e 3) a possível 
relevância de um conjunto de variáveis, como: estratégias de gestão de pessoas, tecnologia, estratégias de RH e condições econômicas que são importantes para a compreensão do processo de AD, e que têm sido pouco exploradas. A partir da revisão de literatura esses autores desenvolveram um modelo em que as variáveis distais (contextuais) influenciam as variáveis proximais relacionadas aos processos e à estrutura da avaliação e, consequentemente, interferem no comportamento dos avaliadores e avaliados.

Para Levy e Williams (2004), as variáveis distais são fatores contextuais que interferem em diversos sistemas de recursos humanos, incluindo a AD. Entre elas estão: cultura da sociedade em que a organização está inserida, fatores econômicos externos, metas organizacionais, composição da força de trabalho, desenvolvimento tecnológico. As variáveis proximais de processo são aquelas que têm impacto direto sobre a forma como a AD é realizada, o que inclui a relação avaliador/ avaliado ou prestação de contas. As variáveis proximais de estrutura relacionam-se com a configuração ou composição da $A D$, com itens como: dimensões da $A D$, treinamento direcionado para $A D$, frequência da $A D$, recursos do sistema, documentação utilizada, entre outros. Definir o contexto organizacional em que a AD ocorre é essencial para compreender e desenvolver mecanismos para AD efetivas; tal contexto ocupa um papel importante no sucesso do processo de avaliação e em como os envolvidos reagem a ele (LEVY; WILLIAMS, 2004).

\section{Metodologia}

Esta seção descreve as principais características do desenho de pesquisa com o objetivo de aumentar a transparência e garantir a replicabilidade dos resultados (KING, 2015; JANZ, 2015; RocHA et al., 2014). Este estudo foi submetido ao Comitê de Ética e Pesquisa envolvendo seres Humanos/ UFPE, cuja aprovação se deu através do parecer consubstanciado $\mathrm{n}^{\circ}$ 1.334.590. O trabalho adotou uma perspectiva multimétodo, combinando a técnica de estudo de caso, observação não participante, análise documental, estatística descritiva e multivariada. A pesquisa foi realizada através de um survey na Universidade Federal de Pernambuco (UFPE) e o questionário (ANEXO 1) foi elaborado a partir de Santos $(2005)^{13}$.

A primeira etapa foi relacionada aos dados demográficos e funcionais dos servidores, contendo informações quanto ao sexo, tempo de serviço, idade, exercício de função de direção, chefia ou assessoramento, categoria da avaliação,

\footnotetext{
${ }^{13}$ Santos (2005) analisou a percepção de servidores envolvidos na avaliação de desempenho de duas instituições públicas e identificou quatro fatores: requisitos e resultados de uma avaliação de desempenho efetiva (RRADE), preparo, ação e prioridades gerenciais (PAPG), impacto sobre o indivíduo e seu comportamento no trabalho (IICT) e influência do relacionamento e da cultura na avaliação de desempenho (IRCAD).
} 
se cedido, cargo, unidade de lotação e escolaridade. A segunda parte se utilizou de questões relacionadas ao contexto da avaliação de desempenho.

A escala utilizada no instrumento foi do tipo Likert ${ }^{14} 5$ pontos (1-discordo totalmente; 2-discordo parcialmente; 3-nem concordo, nem discordo; 4-concordo parcialmente e 5-concordo totalmente). A aplicação do survey foi feita entre os dias 24 de novembro a 30 de dezembro de 2015, de maneira presencial e durante o expediente, no próprio local de trabalho dos servidores. Ocorreu em diferentes horários (manhã/ tarde/ noite) e dias da semana (segunda a sexta-feira).

As respostas foram submetidas à análise fatorial e, posteriormente, a regressão linear foi utilizada para avaliar a relação entre a variável dependente e as independentes (HAIR et al., 2009).

A observação não participante ocorreu concomitantemente à aplicação dos questionários, enquanto os servidores respondiam, relatavam situações e acrescentavam suas experiências, o que permitiu o enriquecimento das informações obtidas.

A população de interesse é formada por 3.961 servidores técnico-administrativos da UFPE, lotados no campus Recife ${ }^{15}$. O nível de confiança da amostra é de $95 \%$, e o erro máximo é de $5 \%$, totalizando 350 observações. Para garantir a representatividade da população, a amostra foi estratificada por centro. A estratificação dos dados e a tabulação foram realizadas com auxílio do Microsoft Excel 2010. Todas as análises estatísticas foram implementadas a partir do Statistical Package for Social Sciences $(\text { SPSS })^{16}$, versão 20 . Na pesquisa de campo foi possível coletar mais casos do que o mínimo estipulado pelo desenho amostral, totalizando 550 unidades. Dessa forma, foi possível reduzir o erro de $5 \%$ para $3,88 \%$.

\section{Resultados}

O perfil incluído na amostra contou com $60,4 \%$ de mulheres e $39,6 \%$ de homens. A idade variou entre 21 e 66 anos, com média de 40,32 e o desvio padrão de 10,85. Com relação ao tempo de serviço, há valores entre 1 e 43 anos, com uma média de 11,32 e desvio padrão de 10,71. No geral, 31,1\% possuem funções de confiança, dos quais $28,9 \%$ são funções gratificadas e $2,2 \%$ cargos de direção. A maioria

\footnotetext{
${ }^{14}$ De acordo com Vieira e Dalmoro (2008), a construção de escalas de mensuração está relacionada ao trabalho seminal de Rensis Likert publicado em 1932, e caracteriza-se pelos respondentes precisarem marcar apenas os pontos fixos estipulados na linha, em um formato de cinco categorias de resposta (pontos), que vão de "aprovo totalmente" a "desaprovo totalmente".

${ }^{15}$ Dados obtidos através do Sistema Integrado de Administração de Recursos Humanos (Siape).

${ }^{16}$ Disponível em: http://www-01.ibm.com/software/analytics/spss/
} 
dos cargos é de nível médio $(55,8 \%)$ e a formação acadêmica predominante foi a especialização $(52,7 \%)$.

Num levantamento feito por Marconi (2010) sobre a escolaridade da força de trabalho no Brasil, entre o período de 1993 (antes da reforma do Estado) e 2007, o nível de escolaridade do setor público supera o privado. O dos estatutários (Governo Federal) é superior aos militares, celetistas e não estatutários sem carteira em qualquer dos três níveis de governo, o que indica um perfil diferenciado desses servidores perante os contratados por outros regimes, possivelmente pelas particularidades das ocupações vinculadas a cada um deles ${ }^{17}$.

A amostra de 550 casos ultrapassou o número considerado suficiente para utilizar uma análise fatorial em um survey composto por 24 itens, uma vez que a razão entre o número de casos e a quantidade de variáveis deve ser de pelo menos cinco para um, tendo como tamanho mais aceitável a proporção de dez para um (HAIR et al., 2009). Neste estudo, a razão foi cerca de 20 casos para cada variável, o que confere maior robustez aos resultados.

Tecnicamente, o primeiro passo foi observar a correlação entre as variáveis que devem ser superiores a 0,30 (HAIR et al., 2009). Também foi aplicado o teste de Kaiser-Meyer-Olkin (KMO), que varia entre 0 e 1, sendo melhor o quanto mais próximo de 1. A estatística Bartlett Test of Spherecity (BTS) foi estatisticamente significativa $(p<0,05)$, indicando que a análise fatorial é adequada ${ }^{18}$ (HAIR et al., 2009). O modelo selecionado foi o que apresentou o melhor ajuste estatístico. A Tabela 1 descreve as medidas de adequação da amostra e o percentual de variância explicada para cada dimensão extraída ${ }^{19}$.

\footnotetext{
${ }^{17}$ Os não estatutários são funcionários que formam o quadro de pessoal há muito tempo e não possuem direitos iguais aos outros que executam as mesmas atividades (MARCONI, 2010).

${ }^{18} \mathrm{O}$ teste de esfericidade de Bartlett analisa a presença de correlações entre as variáveis e fornece a significância estatística de que a matriz de correlação apresenta correlações significantes entre ao menos algumas delas (HAIR et al., 2009).

${ }^{19}$ O critério de percentagem de variância é um método que se baseia no alcance de um percentual cumulativo especificado da variância total extraída por fatores sucessivos. Nas Ciências Sociais, uma solução que explique $60 \%$ dessa variância é considerada satisfatória (HAIR et al., 2009).
} 
Tabela 1 - Medidas de adequação da amostra e percentual de variância explicada

\begin{tabular}{l|c|c|c|c}
\hline Dimensão1 & KMO & BTS (chi2) & p-valor & $\begin{array}{c}\% \text { da } \\
\text { variância }\end{array}$ \\
\hline $\begin{array}{l}\text { Efetividade da avaliação do } \\
\text { estágio probatório }\end{array}$ & 0,805 & 854,264 & 0,000 & 57,09 \\
\hline Ação gerencial & 0,827 & 703,490 & 0,000 & 54,43 \\
\hline Suporte da instituição & 0,782 & 675,409 & 0,000 & 62,55 \\
\hline $\begin{array}{l}\text { Valorização do estágio } \\
\text { probatório enquanto avaliação }\end{array}$ & 0,770 & 692,978 & 0,000 & 62,70 \\
\hline
\end{tabular}

Fonte: dados da pesquisa

A consistência da escala foi medida pelo Alfa de Cronbach $(\alpha=0,914)$ para os 24 itens; segundo Hair et al. (2009), o valor satisfatório é de 0,70. A Tabela 2 detalha os valores para as dimensões ${ }^{20}$.

Tabela 2 - Coeficiente de confiabilidade dos componentes

\begin{tabular}{l|c|c}
\hline Dimensão & Alfa de Cronbach & $\begin{array}{c}\text { Número de } \\
\text { itens }\end{array}$ \\
\hline $\begin{array}{l}\text { Efetividade da avaliação do estágio } \\
\text { probatório }\end{array}$ & 0,811 & 5 \\
\hline Ação gerencial & 0,788 & 5 \\
\hline $\begin{array}{l}\text { Suporte da instituição } \\
\text { Valorização do estágio probatório enquanto } \\
\text { avaliação }\end{array}$ & 0,797 & 4 \\
\hline
\end{tabular}

Fonte: dados da pesquisa

Os Quadros 1, 2, 3 e 4 relacionam os itens, sua descrição e as comunalidades em cada dimensão, respectivamente ${ }^{21}$.

\footnotetext{
${ }^{20}$ Para analisar o alfa de Cronbach, a rotina utilizada é: analisar - escala - análise de confiabilidade.

${ }^{21}$ A comunalidade é o quantitativo total de variância que uma variável compartilha com todas as demais variáveis incluídas na análise (HAIR et al., 2009).
} 
Quadro 1 - Itens efetividade da avaliação do EP e comunalidades

\begin{tabular}{|c|l|c|}
\hline \multicolumn{3}{|c|}{ Efetividade da avaliação do estágio probatório } \\
\hline Item & Descrição & Comunalidade \\
\hline 3 & $\begin{array}{l}\text { Os dados fornecidos pela avaliação do estágio probatório } \\
\text { na UFPE têm sido informaços importantes para o } \\
\text { processo de tomada de decisão. }\end{array}$ & 0,577 \\
\hline 5 & $\begin{array}{l}\text { O sistema de avaliação do estágio probatório na UFPE é } \\
\text { uma ferramenta de gestão que auxilia o avaliador a obter } \\
\text { melhores resultados na área em que ele é responsável. }\end{array}$ & 0,616 \\
\hline 7 & $\begin{array}{l}\text { O resultado da avaliação do estágio probatório na UFPE } \\
\text { corresponde ao desempenho analisado. }\end{array}$ & 0,523 \\
\hline 16 & $\begin{array}{l}\text { O reconhecimento do mérito profissional é um dos } \\
\text { principais resultados da avaliação do estágio probatório } \\
\text { na UFPE. }\end{array}$ & 0,588 \\
\hline 17 & $\begin{array}{l}\text { O retorno (feedback) fornecido/recebido na avaliação do } \\
\text { estágio probatório contribui para melhorar o trabalho } \\
\text { realizado. }\end{array}$ & 0,550 \\
\hline
\end{tabular}

Fonte: dados da pesquisa

Quadro 2 - Itens ação gerencial e comunalidades

\section{Ação gerencial}

\begin{tabular}{|c|l|c|}
\hline Item & Descrição & Comunalidade \\
\hline 8 & $\begin{array}{l}\text { Os avaliadores estão preparados para conduzir o processo } \\
\text { de avaliação do estágio probatório na UFPE. }\end{array}$ & 0,564 \\
\hline 9 & $\begin{array}{l}\text { Os avaliadores na UFPE consideram a função de avaliar } \\
\text { como própria de seu cargo. }\end{array}$ & 0,552 \\
\hline 10 & $\begin{array}{l}\text { Na UFPE os avaliadores conhecem bem o trabalho dos } \\
\text { avaliados. }\end{array}$ & 0,512 \\
\hline 11 & $\begin{array}{l}\text { Os avaliadores valorizam o sistema de avaliação do } \\
\text { estágio probatório na UFPE. }\end{array}$ & 0,476 \\
\hline 12 & $\begin{array}{l}\text { Os avaliadores na UFPE reconhecem a responsabilidade } \\
\text { que possuem ao tornar estável um servidor ou exonerá-lo. }\end{array}$ & \\
\hline
\end{tabular}

Fonte: dados da pesquisa 
Quadro 3 - Itens suporte da instituição e comunalidades

\begin{tabular}{|c|c|c|}
\hline \multicolumn{3}{|c|}{ Suporte da Instituição } \\
\hline Item & Descrição & Comunalidade \\
\hline 1 & $\begin{array}{l}\text { Os resultados da avaliação do estágio probatório são } \\
\text { utilizados como insumos para outros processos de gestão } \\
\text { de pessoas, como: capacitação, plano de sucessão, de } \\
\text { desenvolvimento profissional, mobilidade etc. }\end{array}$ & 0,605 \\
\hline 2 & $\begin{array}{l}\text { A UFPE considera a avaliação do estágio probatório uma } \\
\text { das ações gerenciais prioritárias. }\end{array}$ & 0,652 \\
\hline 4 & $\begin{array}{l}\text { A avaliação do estágio probatório tem sido utilizada } \\
\text { como um importante instrumento de gestão à disposição } \\
\text { da UFPE. }\end{array}$ & 0,730 \\
\hline 6 & $\begin{array}{l}\text { A UFPE incentiva os avaliadores a melhorar } \\
\text { constantemente seus métodos de acompanhamento do } \\
\text { desempenho e de avaliação. }\end{array}$ & 0,515 \\
\hline
\end{tabular}

Fonte: dados da pesquisa

\section{Quadro 4 - Itens valorização do EP enquanto avaliação e comunalidades}

\begin{tabular}{|c|l|c|}
\hline \multicolumn{2}{|c|}{ Valorização do estágio probatório enquanto avaliação } \\
\hline Item & Descrição & Comunalidade \\
\hline 19 & $\begin{array}{l}\text { A utilização da avaliação do estágio probatório permite a } \\
\text { melhoria da qualidade do trabalho. }\end{array}$ & 0,535 \\
\hline 21 & $\begin{array}{l}\text { O estágio probatório possibilita a formação do novo } \\
\text { servidor para executar a função pública. }\end{array}$ & 0,661 \\
\hline 22 & $\begin{array}{l}\text { A avaliação do estágio probatório permite a efetivação de } \\
\text { servidores mais bem preparados para exercer a função } \\
\text { pública. }\end{array}$ & 0,738 \\
\hline 24 & $\begin{array}{l}\text { O estágio probatório é um importante mecanismo para } \\
\text { inserção da meritocracia no serviço público. }\end{array}$ \\
\hline
\end{tabular}

Fonte: dados da pesquisa 
A efetividade da avaliação do estágio probatório é formada por itens atribuídos à utilidade e aos resultados da avaliação do estágio probatório e uso do feedback, os quais são abordados na literatura como critérios característicos de avaliações de desempenho efetivas (OliveIRA-CAStro; LIMA; VeIgA, 1996; Odelius, 2000; DiJK; SCHODL, 2015). A ação gerencial apresenta características quanto ao preparo e atuação do avaliador no exercício da avaliação. Por sua vez, o suporte da instituição aborda aspectos vinculados à assistência, prioridade e ações implementadas pela instituição em favor do sistema de avaliação do estágio probatório. Por fim, a valorização do estágio probatório enquanto avaliação agrupa elementos que abordam o quanto o servidor valoriza o estágio probatório como ferramenta para efetivar melhores servidores.

Enquanto respondiam aos itens, alguns servidores compartilharam sua opinião quanto ao sistema de avaliação do estágio probatório, e a observação não participante foi utilizada para coletar estas informações. Entre os aspectos destacados, foi abordada a utilização dos dados adquiridos na avaliação. Para eles, essas informações deveriam ser utilizadas tanto para o seu desenvolvimento quanto para promoções, entretanto, não é o que de fato acontece.

Quanto à atenção dispensada pela instituição ao sistema de avaliação, a percepção é de que essa ainda é insuficiente. Segundo os respondentes, esse dispositivo ainda não foi incluído na agenda de prioridades, não há um acompanhamento que analise sua implementação e identifique as áreas a serem desenvolvidas. Na opinião deles, é importante que os agentes públicos sejam submetidos a uma avaliação antes de adquirir a estabilidade, assunto abordado no item 20 do survey e que apresentou um percentual bastante expressivo de concordância $(88,6 \%)^{22}$.

O preparo dos avaliadores e suas práticas também foram mencionados. Em geral, tem-se a percepção de que esses servidores não são treinados para exercer essa função e precisam ser conscientizados da importância desse dispositivo. Para eles, a relação entre avaliador/avaliado diz muito sobre o resultado da avaliação. Tal afirmação corrobora o que diz Marconi (2010), o qual relata que essa relação de chefe e subordinado, própria da avaliação individual, pode inibir um processo efetivo de avaliação, visto que a afinidade entre eles pode atrapalhar uma avaliação isenta.

Outra situação apontada refere-se às notas atribuídas. Houve relatos de casos de servidores que, apesar de não apresentarem bom desempenho, acabavam sendo aprovados. Para melhor entender essa situação, foi observada a correlação entre a assertiva 13, que abordava se o possível desgaste ocasionado pela inabilitação

${ }^{22}$ Assertiva 20: É importante que o servidor público seja avaliado antes de adquirir a estabilidade. Esse percentual foi composto por respostas concordo parcialmente $(15,1 \%)$ e concordo totalmente $(73,5 \%)$. 
no estágio probatório influenciava a avaliação e 14 que buscou saber se o servidor identificava se as notas, independente do desempenho, apresentavam valores próximos ao máximo na avaliação do estágio probatório.

A análise apresentou uma correlação positiva entre as afirmativas e é estatisticamente significativa $(r=0,385)$ ( $p$-valor $<0,000)$, o que indica que, quanto mais concordam que o desgaste gerado pela reprovação de um servidor influencia a avaliação, maior é a percepção de que as notas tendem a ter valores próximos ao máximo na avaliação do estágio probatório. Ou seja, é possível que, para evitar conflitos ou desgaste ocasionados pela inabilitação na avaliação, os avaliadores tendem a avaliá-los com notas acima do desempenho apresentado.

Esse achado é semelhante ao resultado mencionado por Barbosa (2003) sobre uma pesquisa realizada com servidores da administração direta e indireta, a qual constatou que os chefes não gostam de avaliar, por entender que essa tarefa sempre causa descontentamento entre os funcionários. Para desviar-se desse tipo de situação, há uma tendência de avaliar todos de maneira positiva.

Para identificar que variáveis explicam a percepção da efetividade da avaliação do estágio probatório (variável dependente - VD), efetuou-se uma análise de regressão linear múltipla para analisar o efeito do suporte da instituição, ação gerencial e valorização do estágio probatório enquanto avaliação sobre essa VD. As demais variáveis: sexo, tempo de serviço, idade, função gratificada e escolaridade também foram incluídas. A seguir, apresentamos o modelo estimado:

$$
Y=\alpha+\beta_{1} X_{1}+\beta_{2} X_{2}+\beta_{3} X_{3}+\beta_{4} X_{4}+\beta_{5} X_{5}+\beta_{6} X_{6}+\beta_{7} X_{7}+\beta_{8} X_{8+} \varepsilon
$$

Y representa a variável dependente, ou seja, a efetividade da avaliação do estágio probatório; $\alpha$, intercepto, representa o valor esperado da variável dependente na ausência de variáveis independentes; $\beta$ representa a variação observada na variável dependente ao se elevar a variável independente em uma unidade; $\mathrm{X}_{1}$ representa o Suporte da Instituição, mensurado através da análise fatorial (AF) com itens do survey; $\mathrm{X}_{2}$ representa a ação gerencial, mensurada através da análise fatorial com itens do survey; $\mathrm{X}_{3}$ representa a valorização do estágio probatório enquanto avaliação, mensurada através da $\mathrm{AF}$ com itens do survey; $\mathrm{X}_{4}$ representa a variável sexo, medida de forma dicotômica ( $0=$ masculino e 1 =feminino); $X_{5}$ representa a variável tempo de serviço, aferida em número de anos completos; $X_{6}$ representa $a$ variável idade, mensurada em número de anos completos; $X_{7}$ representa a variável função gratificada, mensurada de forma dicotômica ( 0 =não possui e 1 =possui) e $\mathrm{X}_{8}$ representa a variável escolaridade, medida de forma ordinal de 1 a 6 , em que quanto maior o valor, maior a escolaridade. Por fim, $\varepsilon$ representa o termo aleatório de erro. A Tabela 3 apresenta o resumo das estatísticas de ajuste do modelo. 
Tabela 3 - Resumo das estatísticas de ajuste do modelo

\begin{tabular}{c|c|c|c|c|c}
\hline $\mathbf{R}$ & $\mathbf{R}^{2}$ & $\begin{array}{c}\mathbf{R}^{2} \\
\text { ajustado }\end{array}$ & $\begin{array}{c}\text { Erro padrão } \\
\text { da estimativa }\end{array}$ & $\mathbf{F}$ & $\mathbf{p}$-valor \\
\hline $0,863^{\mathrm{a}}$ & 0,745 & 0,741 & 0,509 & 197,334 & 0,000 \\
\hline
\end{tabular}

Fonte: dados da pesquisa

$\mathrm{R}$ - representa a correlação do modelo estimado com a variável dependente, no caso, a percepção da efetividade da avaliação do estágio probatório. Como pode ser observado, a correlação é de 0,863 , o que indica uma forte associação entre as variáveis explicativas e a variável dependente. $O R^{2}$ representa a proporção da variável dependente explicada pelo conjunto das variáveis independentes. Nesse modelo, essa estatística foi de 0,745 , explicando cerca de $75 \%$ da variação da variável dependente. $O \mathrm{R}^{2}$ ajustado - igual ao $\mathrm{R}^{2}$ e ajusta pela contribuição adicional de cada variável (número de observações e variáveis incluídas no modelo). Quanto mais parecido com o $R^{2}$, melhor. $O R^{2}$ ajustado $(0,741)$ foi muito próximo do $R^{2}$ $(0,745)$. A Tabela 4 apresenta os coeficientes do modelo.

Tabela 4 - Coeficientes de regressão

\begin{tabular}{|c|c|c|c|c|c|c|}
\hline & \multirow{2}{*}{ Modelo } & \multicolumn{2}{|c|}{$\begin{array}{l}\text { Coeficientes não } \\
\text { padronizados }\end{array}$} & \multirow{2}{*}{$\begin{array}{c}\begin{array}{c}\text { Coeficientes } \\
\text { padronizados }\end{array} \\
\text { Beta }\end{array}$} & \multirow{2}{*}{$\mathbf{t}$} & \multirow{2}{*}{ p-valor } \\
\hline & & B & $\begin{array}{c}\text { Erro } \\
\text { Padrão }\end{array}$ & & & \\
\hline \multirow{9}{*}{1} & (Constante) & $-0,243$ & 0,147 & & $-1,651$ & 0,099 \\
\hline & $\begin{array}{l}\text { Suporte da } \\
\text { Instituição }\end{array}$ & 0,464 & 0,028 & 0,464 & 16,720 & 0,000 \\
\hline & Ação Gerencial & 0,343 & 0,027 & 0,343 & 12,546 & 0,000 \\
\hline & $\begin{array}{l}\text { Valorização do } \\
\text { EP enquanto } \\
\text { avaliação }\end{array}$ & 0,240 & 0,026 & 0,240 & 9,376 & 0,000 \\
\hline & Sexo & 0,037 & 0,045 & 0,018 & 0,809 & 0,419 \\
\hline & Tempo de serviço & $-0,007$ & 0,004 & $-0,072$ & $-1,880$ & 0,061 \\
\hline & Idade & 0,006 & 0,004 & 0,070 & 1,830 & 0,068 \\
\hline & Função gratificada & 0,044 & 0,048 & 0,020 & 0,910 & 0,363 \\
\hline & Escolaridade & 0,007 & 0,026 & 0,006 & 0,257 & 0,797 \\
\hline
\end{tabular}

Fonte: dados da pesquisa 
A hipótese de pesquisa foi confirmada, visto que fatores contextuais foram mais importantes para explicar a percepção da efetividade da avaliação do estágio probatório do que variáveis pessoais (SANTOS, 2005). Em particular, quando o suporte da instituição aumenta em um desvio padrão, a percepção da efetividade da avaliação do estágio probatório aumenta em 0,464 desvio padrão, controlando pelas demais variáveis ( $p$-valor $<0,001)$. Similarmente, quando a ação gerencial aumenta em um desvio padrão, a percepção da efetividade da avaliação do estágio probatório aumenta em 0,343 desvio padrão, controlando pelas demais variáveis ( $p$-valor $<0,001)$. Por fim, quando a valorização do estágio probatório enquanto avaliação aumenta em um desvio padrão, a percepção da efetividade da avaliação do estágio probatório aumenta em 0,240 desvio padrão, controlando pelas demais variáveis ( $p$-valor $<0,001$ ). Em termos substantivos, esses resultados indicam que o suporte da instituição é a dimensão mais importante para explicar a variação da variável dependente.

Em relação às variáveis individuais, observa-se que as mulheres (grupo=1) têm uma percepção ligeiramente mais positiva do que os homens (grupo=0). No entanto, o coeficiente não foi estatisticamente significativo ( $p$-valor=0,419). Quanto maior o tempo de serviço, menor é a percepção da efetividade da avaliação do estágio probatório $(p \text {-valor }=0,061)^{23}$. Quando acrescido um ano à idade, a percepção da Efetividade da Avaliação do Estágio Probatório aumenta em 0,006 ; o coeficiente foi significativo a $10 \%$ (p-valor=0,068). Quanto à função gratificada, os que possuem função (grupo=1), apresentam uma percepção um pouco mais positiva do que os que não possuem (grupo=0). No entanto, o coeficiente não foi estatisticamente significativo ( $p$-valor=0,363). Quando aumenta a escolaridade em uma unidade, a percepção da efetividade da avaliação do estágio probatório aumenta em 0,007. Entretanto, o coeficiente não foi estatisticamente significativo ( $p$-valor=0,797). A Figura 1 sumariza os coeficientes do modelo.

\footnotetext{
${ }^{23}$ Nas Ciências Sociais, normalmente são adotados três diferentes patamares para analisar o p-valor: 0,1 (significativo no nível de 10\%); 0,05 (significativo no nível de 5\%) e 0,01 (significativo no nível de 1\%) (FIGUEIREDo FILHO; SILVA JÚNIOR, 2009).
} 
Figura 1- Representação gráfica dos resultados ${ }^{24}$

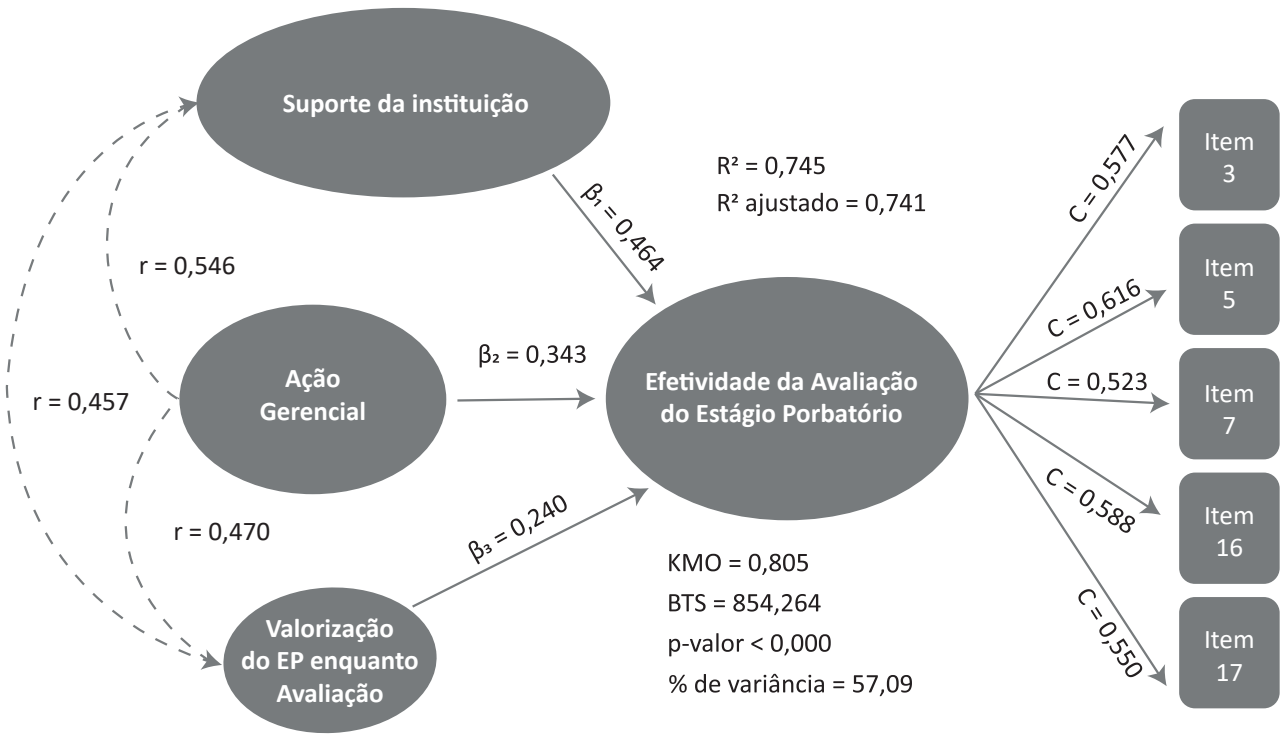

Fonte: elaboração própria a partir de dados da pesquisa

Os Quadros indicam as variáveis observadas do survey (itens 3, 5, 7, 16 e 17) e apresentaram as seguintes comunalidades: $\left(C_{3}=0,577 ; C_{5}=0,616 ; C_{7}=0,523\right.$; $C_{16}=0,588$ e $C_{17}=0,550$, respectivamente). Esses itens formaram a dimensão efetividade da avaliação do estágio probatório (EAEP), que apresentou como medidas de adequação da amostra (KMO=0,805; BTS=854,264; $p$-valor $<0,000$ e variância explicada=57,09\%). Além dessa, foram formadas suporte da instituição (SI), ação gerencial (AG) e valorização do estágio probatório enquanto avaliação (VEPA), variáveis não observáveis e representadas pelas elipses. A efetividade da avaliação do estágio probatório (VD) foi submetida a um modelo de regressão múltipla, tendo os demais fatores como variáveis independentes. A regressão apresentou $R^{2}=0,745$ e $R^{2}$ ajustado=0,741. As setas unidirecionais representam os coeficientes de regressão, ou seja, o impacto das Variáveis Independentes (VIs) sobre a VD ( $\mathrm{SI}=0,464 ; A G=0,343$ e VEPA=0,240). Além disso, as linhas pontilhadas representam a correlação entre as dimensões latentes (SI x AG: $r=0,546$; SI x VEPA: $r=0,457$ e $A G$ x VEPA: $r=0,470)$.

\section{Considerações finais}

Este estudo analisou os fatores que influenciam a percepção da efetividade da avaliação do estágio probatório. $\mathrm{O}$ desenho de pesquisa utilizou um survey e

\footnotetext{
${ }^{24}$ As variáveis: sexo, tempo de serviço, idade, função gratificada e escolaridade, foram suprimidas por questão de formatação.
} 
identificou quatro dimensões: efetividade da avaliação do estágio probatório, suporte da instituição, ação gerencial e valorização do estágio probatório enquanto avaliação. Fatores relacionados ao contexto da avaliação do estágio probatório foram mais importantes para explicar a percepção de sua efetividade do que variáveis pessoais, confirmando a hipótese de pesquisa.

Em particular, o suporte da instituição apresentou o maior nível de explicação. Além disso, as dimensões efetividade da avaliação do estágio probatório e ação gerencial são similares às encontradas por Santos (2005), ainda que os itens utilizados não tenham sido exatamente iguais. Tecnicamente, esses resultados sugerem que as dimensões identificadas são confiáveis.

Para além da análise estatística, foram realizadas também conversas informais e observação não participante com o objetivo de identificar os sentimentos dos servidores em relação a elementos não contemplados no instrumento e/ ou não diretamente observáveis. Entre os relatos, observamos a utilização das informações adquiridas na avaliação e como a instituição direciona esforços para a sua efetividade. Para eles, esses resultados deveriam ser melhor aproveitados, e consideram que o sistema recebe pouco investimento. Faltam ações para aprimorar os métodos utilizados, esclarecimento e treinamento para os avaliadores, o que acaba prejudicando sua efetividade.

Operacionalmente, os resultados indicam que, para que a avaliação do estágio probatório seja efetiva, algumas intervenções devem ser realizadas. O Suporte da Instituição causou maior impacto sobre a EAEP, o que requer a intensificação de esforços para: 1) criar grupos de trabalho para estudar o sistema de avaliação e os métodos utilizados, a fim de desenvolver práticas e procedimentos; 2) utilizar as informações advindas da avaliação em outros processos de gestão; 3) oferecer um ambiente favorável ao desenvolvimento do estagiário para o exercício de suas funções; e 4) priorizar esse sistema de avaliação, fornecendo o apoio necessário para o seu bom funcionamento.

A ação gerencial foi a segunda dimensão que mais explicou a EAEP. Quanto aos avaliadores: 1 ) devem receber treinamento, interagir com outros profissionais e trocar experiências com instituições para desenvolver suas técnicas de avaliação; 2) ser instruídos quanto à responsabilidade que possuem ao inabilitar ou tornar estável um servidor; e 3) conscientizá-los sobre o impacto causado à instituição quando se efetiva servidores sem a devida capacidade.

Além disso, políticas de sensibilização que esclareçam as finalidades desse instrumento devem ser priorizadas. A valorização do estágio probatório enquanto avaliação também causou efeito positivo sobre a EAEP, com isso, devem ser implementados: 1) treinamentos junto aos profissionais que atuam 
diretamente no sistema de avaliação, para melhorar sua implementação; 2) palestras que conscientizem os servidores quanto à importância desse mecanismo e esclareçam sobre suas principais finalidades; e 3) implantar ações voltadas à valorização do sistema, o que possibilitará uma postura diferenciada dos servidores frente a esse dispositivo.

Este trabalho apresentou algumas limitações. A obtenção de dados primários é um procedimento que apresenta vários obstáculos, um deles é a disponibilidade dos entrevistados para participar do estudo e o tempo dedicado à coleta, que acaba tendo que ser dividido com as atividades profissionais. Atingir o quantitativo mínimo de observações (350) também foi um desafio, uma vez que o survey foi aplicado pessoalmente e não contou com financiamento externo.

A utilização de apenas um caso também é um fator restritivo (GERRING, 2004). Isso impossibilita a comparação com outras realidades e a generalização dos resultados observados. Além disso, a interpretação desses deve ser feita com prudência, visto que a efetividade aqui mensurada é a percepção da efetividade e não a efetividade real.

Para pesquisas futuras, outras variáveis relacionadas ao contexto da avaliação do estágio probatório, não utilizadas neste estudo, podem ser testadas como variáveis independentes. Esta pesquisa também poderá ser replicada em diferentes instituições públicas ou, utilizando-se outras estratégias metodológicas, será possível identificar achados diferenciados ou complementares à ótica aqui adotada. Sugere-se que o suporte da instituição - dimensão que demonstrou maior efeito sobre a EAEP - seja investigado em outras análises e sua contribuição observada de forma mais específica.

Este artigo apresenta uma contribuição original sobre a percepção da efetividade da avaliação do estágio probatório em instituições públicas federais brasileiras. É inovador na metodologia empregada e pode auxiliar na formulação de políticas especialmente voltadas para melhorar a qualidade da burocracia no país, uma vez que, além de abordar um tema ainda pouco explorado, propõe ações para desenvolver as práticas atualmente utilizadas. Nesse sentido, tentamos colaborar com a disseminação de conhecimento sobre o tema e incentivar outros pesquisadores, possibilitando que outros estudos explorem essa temática sob diferentes perspectivas. 


\section{Referências bibliográficas}

ABrucio, F. L. Uma leitura da gestão de pessoas sob a perspectiva do mérito, desempenho e resultados. In: TEIXEIRA, H. J.; BASSOTI, I. M.; SANTOS, T. S. (Orgs) Mérito, desempenho e resultados: ensaios sobre gestão de pessoas para o setor público. 1a Ed. São Paulo. FIA/USP. 2014.

ABRUCIO, F. L. Trajetória recente da gestão pública brasileira: um balanço crítico $e$ a renovação da agenda de reformas. RAP. Rio de Janeiro. 2007. Edição Especial Comemorativa 67-86, 1967-2007.

ABRUcio, F. L. Os avanços e os dilemas do modelo pós-burocrático: a reforma da administração pública à luz da experiência internacional recente. In: BRESSERPereIRA, L.C.; SPINK, P. K. (orgs.) Reforma do Estado e Administração Pública Gerencial. 7ạ. Edição. Rio de Janeiro, Editora FGV, 2006.

ALVES, A. R. Notas sobre estágio probatório na Constituição Federal de 1988. Jus Navigandi, Teresina, ano 12, n. 1629, 17 dezembro de 2007.

BARBOSA, L. Igualdade e meritocracia: a ética do desempenho nas sociedades modernas. 4ä. Ed., Editora FGV, Rio de Janeiro, 216 p. 2003.

Bateson, M.; NetTle, D.; Roberts, G. Cues of being watched enhance cooperation in a real-world setting. Biology letters, v. 2, n. 3, p. 412-414, 2006.

Bergue, S. T. Gestão estratégica de pessoas no setor público. São Paulo. Ed. Atlas, 2014.

BEZERRA, R. O. Fatores organizacionais e individuais no processo de avaliação de desempenho do estágio probatório: estudo de caso no Instituto Federal de Minas Gerais - Campus Ouro Preto. Dissertação. Belo Horizonte. 2013.

Bittencourt, C. A. L. Do estágio probatório e sua efetiva utilização. Revista do Serviço Público, Rio de Janeiro: Dasp, v. 3, n. 1 e 2, p. 38-71, set/out.1948.

BRASIL. Emenda Constitucional no 19, de 04 de junho de 1998. Modifica o regime e dispõe sobre princípios e normas da Administração Pública, servidores e agentes políticos, controle de despesas e finanças públicas e custeio de atividades a cargo do Distrito Federal, e dá outras providências. Disponível em: <http://www. planalto. gov.br/ccivil_03/constituicao/emendas/emc/emc19.htm> Acesso em: 03 de abril de 2015.

. Lei no 284, de 28 de outubro de 1936, que reajusta os quadros e os vencimentos do funcionalismo público civil da União e estabelece diversas providencias. Disponível em: <http://www2.camara.leg.br/legin/fed/lei/19301939/lei284-28-outubro-1936-503510-publicacaooriginal-1-pl.html> Acesso em: 05 de fevereiro de 2016

. Decreto-lei no 1.713, de 28 de outubro de 1939, dispõe sobre o Estatuto dos Funcionários Públicos Civis da União. Disponível em: <http://www2.camara. leg.br/legin/fed/declei/1930-1939/decreto-lei-1713-28-outubro1939-411639publicacaooriginal-1-pe.html> Acesso em: 11 de fevereiro de 2016.

Bresser Pereira, L. C. Reforma do Estado para a cidadania. A Reforma Gerencial Brasileira na Perspectiva Internacional. Enap. 1a. Ed. Brasília. 1998. 
BResser PereiRA, L. C. Gestão do setor público: estratégia e estrutura para um novo Estado. In: Bresser-Pereira, L.C.; Spink, P. (org.), Reforma do Estado e administração pública gerencial. 3a. ed., Rio de Janeiro, FGV. 1998a.

BRESSER PEREIRA, L.C. Da administração burocrática à gerencial. In: BresSER PEREIRA, L.C.; SPINK, P. K. (orgs.) Reforma do Estado e Administração Pública Gerencial. 7ạ. Edição. Rio de Janeiro, Editora FGV, 2006.

CAVALCANTE, P.; CARVALHO, P. The professionalization of Brazilian federal bureaucracy (1995-2014): advances and dilemmas. Brazilian Journal of Public Administration. Rio de Janeiro, v. 51, n. 1, p. 1-26, jan. - fev. 2017.

DEADRICK, D. L.; GARDNER, D. G.. Maximal and typical measures of job performance: an analysis of performance variability over time. Human Resource Management Review, v. 18, p. 133-145, 2008.

DENISI, A. S. Performance appraisal and performance management: a multilevel analysis. In: KLEIN, K.J.; KozLOWSKI, S. W. J. (ed) Multilevel Theory, Research, and Methods in Organizations. 2000. São Francisco, Jossey-Bass.

DeNISI, A. S.; PRITCHARD, R. D. Performance appraisal, performance management and improving individual performance: a motivational framework. Management and Organization Review, v. 2, ed. 2,, p. 253-277, 2006.

DIJK, D.; SCHODL, M. M. Performance appraisal and evaluation. International Encyclopedia of the Social \& Behavioral Sciences (Second Edition). Pages 716-721, 2015.

ElLIOT, R. H.; PeAton, A. L. The probationary period in the selection process: a survey of its use at the state level. Public Personnel Management, v. 23, n. 1, p. 4759, 1994.

Escola nacional de AdMinistração PúBlicA. Relatório de avaliação da política de Gratificação de Desempenho de Atividade Técnico-Administrativa (GDATA). Brasília, Enap, 2003.

Ficagna, A. V. O. et al.; Sistema de avaliação do estágio probatório: o caso da Prefeitura Municipal de Sarandi-RS. In: Encontro da Anpad, 38, 2014, Rio de Janeiro. Anais...Rio de Janeiro: Anpad, 2014

FigueIREDo Filho, D. B.; Silva JúnIOR, J. A. Desvendando os mistérios do coeficiente de correlação de Pearson. Revista Política Hoje, v. 18, n. 1, 2009.

Gerring, J. What Is a Case Study and What Is It Good for? The American Political Science Review, v. 98, n. 2, p. 341-354, may, 2004.

Guimarães, T. A.; NADER, R. M.; RAMAgem, S. P. Avaliação de desempenho de pessoal: uma metodologia integrada ao planejamento e à avaliação organizacionais. RAP. Rio de Janeiro, v. 32, n. 6, p. 43-61, 1998.

GuimarÃEs, T. A.; LeitÃo, J. S. S.; Lourenço, R. L. R. Avaliação de desempenho baseada em resultados em organização de pesquisa e desenvolvimento: a percepção de pesquisadores sobre sua finalidade, objetivos e limitações. Revista de Administração, São Paulo, v. 34, n. 3, p. 83-94, julho/setembro, 1999.

HAIR, J. F. et al. Análise multivariada de dados. 6a. Ed. Bookman. 2009.

JANZ, N. Bringing the gold standard into the classroom: replication in university 
teaching. International Studies Perspectives. .v. 0, p. 1-16, 2015.

JOHNSON, R.; LIBECAP, G. The federal civil service system and the problem of bureaucracy: the economics and politics of institucional change. The London and Chicago: University of Chicago Press, 1994.

Kıng, G. Replicação, replicação. Revista Eletrônica de Ciência Política, v. 6, n. 2, 2015. LEVY, P. E.; WILLIAMS, J.R. The social context of performance appraisal: a review and framework for the future. Journal of Management.v. 30, n. 6, p. 881-905, 2004.

MAIA, A. A. O problema do estágio probatório. Revista do Serviço Público. p. 6-23, julho, 1958.

MARCONI, N. Uma radiografia do emprego público no Brasil: análise e sugestões de políticas. In: LouReIRo, M.R.; ABRUCIO, F. L.; PACHECO, R. S. (orgs.) Burocracia e política no Brasil: desafios para a ordem democrática no século XXI. Brasília: Ed. FGV, 1‥ Ed. 2010. p. 219-275.

MOdESTO, P. Estágio probatório: questões controversas. Revista Eletrônica de Direito do Estado. Número 10. 2007. Disponível em: <http://www.direitodoestado. com/revista/REDE-10-ABRIL-2007-PAULO\%20MODESTO.pdf>. Acesso em: 31 de outubro de 2016.

ODELIUS, C.C. Experiências de avaliação de desempenho na administração pública federal. Cadernos Enap. Brasília: Enap, 2000.

OliveirA-CAstro, G. A. O.; LiMA, G. B. C; VeigA, M. R. M. Implantação de um sistema de avaliação de desempenho: métodos e estratégias. Revista de Administração. São Paulo, v. 31, n. 3, p. 38-52, 1996.

PACHECO, R. S. A agenda da nova gestão pública. In: LoureIRo, M.R.; Abrucio, F. L.; PACHECO, R. S. (orgs.) Burocracia e política no Brasil: desafios para a ordem democrática no século XXI. Brasília: Ed. FGV, 1a. ed. 2010. p. 183-218.

PINTO, J. F.; BEHR, R. R. Contradições na avaliação de desempenho dos servidores técnico-administrativos em educação na universidade pública. Cadernos Ebape.Br, v.13, n. 4, Artigo 8, Rio de Janeiro, Out/ Dez. 2015.

REZENDE, F. C. Por que falham as reformas administrativas? Editora FGV, 1a ed. Rio de Janeiro, 2004.

RIBEIRo, L. G. R. Estágio probatório (Doutrina, legislação e crítica). Revista do Serviço Público. Rio de Janeiro: Dasp, v. 3 Ano 08, n. 2, p. 58-67, Agosto, 1945.

RochA, E. C. et al. A Importância da replicabilidade na Ciência Política: o caso do SIGOBR. Revista Política Hoje - 2a Edição - v. 22, p. 213-229, 2014.

Rodrigues, R. J. P. Regime jurídico do servidor público nos Estados Unidos. Consultoria Legislativa. Câmara dos Deputados. Estudo. Novembro. 1995. Brasília.

RYNES, S. L.; GeRHART, B.; PARKS, L. Personnel psychology: performance evaluation and pay for performance. Annual Review of Psychology, v. 56, p. 571-600, 2005.

SANTOS, P. R. G. Avaliação de desempenho no contexto da administração pública federal direta: aspectos determinantes de sua efetividade. Dissertação. Unb. Brasília. 2005. 
Sılva, M.B.P. Período probatório no serviço público federal: validação de itens avaliados segundo a percepção dos servidores do Iffluminense. Dissertação. Campos dos Goytazes-RJ, 2016.

SonnentaG, S.; Frese, M. Performance concepts e performance theory. In. S. SONNENTAG, S. (Ed.).Psychological management of individual performance.p. 3-25. New York: 2002.

STAHL, O.G. Public personnel administration, 8th ed. New York: Harper and Ro.1983.

SUDANO, C. G. P. Estágio probatório e reformas na gestão pública: um estudo de caso da avaliação no início de carreira no estado de São Paulo. Dissertação. Fundação Getúlio Vargas. São Paulo, 2011.

VIEIRA, K. M.; DALMORO, M. Dilemas na construção de escalas tipo Likert: o número de itens e a disposição influenciam nos resultados? EnCONTRO DA Anpad, 22., 2008, Rio de Janeiro. Anais...Rio de Janeiro: Anpad, 2008

WHEELER, E. P. The rise and progress of the merit system. Political Science Quarterly. v. 34, n. 3, p. 486-492, set., 1919.

\section{Luciana Cristina Silva da Luz}

Mestre em Políticas Públicas pela Universidade Federal de Pernambuco (UFPE). Atualmente é servidora técnicaadministrativa e assistente da Pró-reitoria de Gestão de Pessoas e Qualidade de Vida da UFPE. Contato: lulu.cluz@ gmail.com

\section{Dalson Britto Figueiredo Filho}

Doutor em Ciência Política pela Universidade Federal de Pernambuco (UFPE). Professor do Departamento de Ciência Política (DCP) e coordenador científico do Mestrado Profissional em Políticas Públicas da UFPE (MPPP/ UFPE). Atualmente é pesquisador visitante da Universidade de Nottingham, Reino Unido. Contato: dalsonbritto@ yahoo.com.br 


\section{ANEXO 1 - QUESTIONÁRIO}

Este questionário faz parte da pesquisa intitulada: Efetividade da Avaliação do Estágio Probatório em uma instituição pública federal. Os dados desta pesquisa são sigilosos e os respondentes não serão identificados.

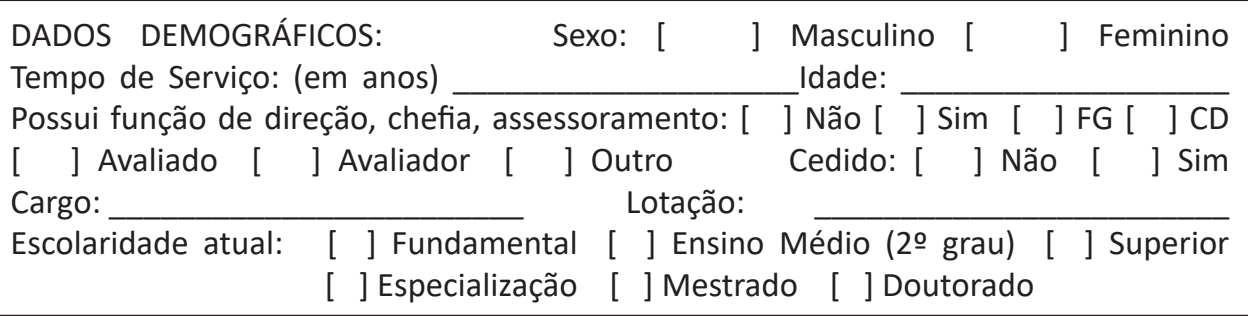

\section{ATENÇÃO!}

A escala vai de 1(discordo totalmente), 2(discordo parcialmente), 3 (nem concordo, nem discordo), 4 (concordo parcialmente) e 5(concordo totalmente).

concordo totalmente

concordo parcialmente

nem concordo, nem discordo

discordo parcialmente

discordo totalmente

\begin{tabular}{|c|l|l|l|l|l|l|}
\hline 1 & $\begin{array}{l}\text { Os resultados da Avaliação do Estágio Probatório são utilizados } \\
\text { como insumos para outros processos de gestão de pessoas, } \\
\text { como: capacitação, plano de sucessão, de desenvolvimento } \\
\text { profissional, mobilidade, etc. }\end{array}$ & 1 & 2 & 3 & 4 & 5 \\
\hline 2 & $\begin{array}{l}\text { A UFPE considera a Avaliação do Estágio Probatório uma das } \\
\text { ações gerenciais prioritárias. }\end{array}$ & 1 & 2 & 3 & 4 & 5 \\
\hline 3 & $\begin{array}{l}\text { Os dados fornecidos pela Avaliação do Estágio Probatório na } \\
\text { UFPE têm sido informações importantes para o processo de } \\
\text { tomada de decisão. }\end{array}$ & 1 & 2 & 3 & 4 & 5 \\
\hline 4 & $\begin{array}{l}\text { A Avaliação do Estágio Probatório tem sido utilizada como um } \\
\text { importante instrumento de gestão à disposição da UFPE. }\end{array}$ & 1 & 2 & 3 & 4 & 5 \\
\hline 5 & $\begin{array}{l}\text { O sistema de Avaliação do Estágio Probatório na UFPE é uma } \\
\text { ferramenta de gestão que auxilia o avaliador a obter melhores } \\
\text { resultados na área em que ele é responsável. }\end{array}$ & 1 & 2 & 3 & 4 & 5 \\
\hline
\end{tabular}




\begin{tabular}{|c|c|c|c|c|c|c|}
\hline 6 & $\begin{array}{l}\text { A UFPE incentiva os avaliadores a melhorar constantemente } \\
\text { seus métodos de acompanhamento do desempenho e de } \\
\text { avaliação. }\end{array}$ & 1 & 2 & 3 & 4 & 5 \\
\hline 7 & $\begin{array}{l}\text { O resultado da Avaliação do Estágio Probatório na UFPE } \\
\text { corresponde ao desempenho analisado. }\end{array}$ & 1 & 2 & 3 & 4 & 5 \\
\hline 8 & $\begin{array}{l}\text { Os avaliadores estão preparados para conduzir o processo de } \\
\text { Avaliação do Estágio Probatório na UFPE. }\end{array}$ & 1 & 2 & 3 & 4 & 5 \\
\hline 9 & $\begin{array}{l}\text { Os avaliadores na UFPE consideram a função de avaliar como } \\
\text { própria de seu cargo. }\end{array}$ & 1 & 2 & 3 & 4 & 5 \\
\hline 10 & $\begin{array}{l}\text { Na UFPE os avaliadores conhecem bem o trabalho dos } \\
\text { avaliados. }\end{array}$ & 1 & 2 & 3 & 4 & 5 \\
\hline 11 & $\begin{array}{l}\text { Os avaliadores valorizam o sistema de Avaliação do Estágio } \\
\text { Probatório na UFPE. }\end{array}$ & 1 & 2 & 3 & 4 & 5 \\
\hline 12 & $\begin{array}{l}\text { Os avaliadores na UFPE reconhecem a responsabilidade que } \\
\text { possuem ao tornar estável um servidor ou exonerá-lo. }\end{array}$ & 1 & 2 & 3 & 4 & 5 \\
\hline 13 & $\begin{array}{l}\text { O possível desgaste ocasionado pela reprovação na Avaliação } \\
\text { do Estágio Probatório influencia a avaliação. }\end{array}$ & 1 & 2 & 3 & 4 & 5 \\
\hline 14 & $\begin{array}{l}\text { Você identifica que, independente do desempenho, as notas } \\
\text { têm valores próximos ao máximo, no sistema de Avaliação do } \\
\text { Estágio Probatório da UFPE. }\end{array}$ & 1 & 2 & 3 & 4 & 5 \\
\hline 15 & $\begin{array}{l}\text { A Avaliação do Estágio Probatório na UFPE decorre de um } \\
\text { processo onde há diálogo entre avaliador e avaliado. }\end{array}$ & 1 & 2 & 3 & 4 & 5 \\
\hline 16 & $\begin{array}{l}\text { O reconhecimento do mérito profissional é um dos principais } \\
\text { resultados da Avaliação do Estágio Probatório na UFPE. }\end{array}$ & 1 & 2 & 3 & 4 & 5 \\
\hline 17 & $\begin{array}{l}\text { O retorno (feedback) fornecido/ recebido na Avaliação } \\
\text { do Estágio Probatório contribui para melhorar o trabalho } \\
\text { realizado. }\end{array}$ & 1 & 2 & 3 & 4 & 5 \\
\hline 18 & $\begin{array}{l}\text { A estabilidade que pode ser recebida em função da Avaliação } \\
\text { do Estágio Probatório é relevante para motivar alguém a } \\
\text { trabalhar melhor. }\end{array}$ & 1 & 2 & 3 & 4 & 5 \\
\hline 19 & $\begin{array}{l}\text { A utilização da Avaliação do Estágio Probatório permite a } \\
\text { melhoria da qualidade do trabalho. }\end{array}$ & 1 & 2 & 3 & 4 & 5 \\
\hline 20 & $\begin{array}{l}\text { É importante que o servidor público seja avaliado antes de } \\
\text { adquirir a estabilidade. }\end{array}$ & 1 & 2 & 3 & 4 & 5 \\
\hline 21 & $\begin{array}{l}\text { O estágio probatório possibilita a formação do novo servidor } \\
\text { para executar a função pública. }\end{array}$ & 1 & 2 & 3 & 4 & 5 \\
\hline
\end{tabular}




\begin{tabular}{|c|l|l|l|l|l|l|}
\hline 22 & $\begin{array}{l}\text { A avaliação do estágio probatório permite a efetivação de } \\
\text { servidores mais bem preparados para exercer a função } \\
\text { pública. }\end{array}$ & 1 & 2 & 3 & 4 & 5 \\
\hline 23 & $\begin{array}{l}\text { A UFPE propicia adaptação do servidor minimizando as } \\
\text { divergências entre as expectativas iniciais e a real natureza de } \\
\text { suas funções. }\end{array}$ & 1 & 2 & 3 & 4 & 5 \\
\hline 24 & $\begin{array}{l}\text { O estágio probatório é um importante mecanismo para } \\
\text { inserção da meritocracia no serviço público. }\end{array}$ & 1 & 2 & 3 & 4 & 5 \\
\hline
\end{tabular}


RSP 